\title{
El cómic como fuente histórica: el falso testimonio de Tintín en el Congo Belga
}

\author{
Óscar Gual Boronat \\ IMAB — Institut Municipal d'Arxius i Biblioteques de Gandia \\ The comics as historical source. The false Tintin's testimony \\ in Belgian Congo
}

\begin{abstract}
RESUMEN
A través del estudio de la obra Tintin au

Congo del dibujante belga Hergé, tratamos de probar la capacidad del cómic para ser utilizado como fuente histórica.

La actual definición de fuente puede englobarlo perfectamente pero es necesaria una demostración práctica. Tras contextualizar dicha historieta pasamos a realizar una lectura atenta de la misma, así como de sus aspectos más polémicos, para a continuación describir el proceso de trabajo del propio Hergé y las influencias de su entorno. Por último, entraremos a debatir cuál es el origen de la historieta como medio y cuál es el método de análisis a la hora de interrogarla históricamente.

PALABRAS CLAVE: Cómic, Historieta, Tintín, Hergé, Congo, Fuente Histórica
\end{abstract}

\begin{abstract}
Through the study of the Belgian cartoonist Hergé's work Tintin au Congo we try to test the ability of comics to be used as a historical source. The current source definition can cover it very well but requires a practical demonstration. After we contextualize this story we make a careful reading of it and of its most controversial features, then we describe the process of Hergé's own work and the influences of their environment. Finally we enter into a discussion about which is the origin of comics as a medium and which is the method of analysis when questioning historically.
\end{abstract}

KEY WORDS:

Comics, Tintin, Hergé, Belgian Congo, Historical Source

\section{INTRODUCCIÓN}

En el verano de 2007 el ciudadano belga de origen congoleño, Bienvenu Mbutu Mondondo, interpuso una demanda contra la sociedad Moulinsart, propietaria de los derechos de autor derivados de la obra de Georges Remi - Hergé-, acusando al cómic Tintín au Congo de racista y xenófobo, y de ser una apología de la colonización. Dos años más tarde, y sin que dicha demanda estuviera todavía re- 
suelta, presentó en los mismos términos una nueva reclamación en los tribunales franceses, con el objetivo de conseguir la prohibición de dicha obra.

La primera versión de Tintín au Congo -inicialmente conocida como Les aventures de Tintin, reporter du Petit Vingtième, au Congo - , publicada justo después del éxito de Tintín au pays des Soviets, apareció por entregas en el semanario belga Le Petit Vingtième (suplemento infantil del periódico católico Le Vingtième Siècle), entre junio de 1930 y julio de 1931. Por aquel entonces, el vínculo entre la colonia africana y la metrópolis europea estaba totalmente consolidado; habían pasado ya más de veinte años desde que en 1908, el Congo -llamado por entonces de forma eufemística Estado Libre del Congo- dejara de ser una propiedad exclusiva del rey Leopoldo II para pasar a ser gestionada y controlada de forma directa por la administración belga. Los constantes abusos sobre la población indígena, que según el estudio de Adam Hochschild fue reducida a la mitad entre 1885 y $1906^{1}$, provocaron una serie de protestas internacionales y presiones diplomáticas que empujaron al monarca a ceder sus derechos exclusivos y nacionalizar el territorio.

Dicha transferencia no significó una transformación inmediata de la vida en la colonia, pero sí dio inicio a una serie de cambios importantes. El gobierno de la región estaba ahora en manos del gobernador general, apoyado por un consejo consultivo, mientras que el poder legislativo pertenecía al Parlamento local, facultado para votar leyes propias, que posteriormente habían de ser sancionadas desde Bruselas. Por otro lado se creó la figura del procurador general, encargado de los servicios legales, quien controlaba a los funcionarios gubernamentales -impidiendo las arbitrariedades de la época anterior-, y presidía a su vez el Comité para la protección de los indígenas. El territorio se dividió en seis grandes provincias - a las que se sumarian en 1925 los territorios de Ruanda y Burundi- dependientes cada una de ellas, de un vicegobernador general. Cada provincia se dividía en distritos, controlados por los comisarios, y los distritos en subdistritos, responsabilidad de los administradores. Toda una jerarquía creada para «la administración de los africanos —no de los europeos_- en el ámbito de la estructura tribal $»^{2}$.

Sin embargo, la principal alteración respecto a la etapa anterior se produjo a nivel demográfico, con un mayor control del tráfico de esclavos - actividad que ya estaba prohibida-, y con el incremento de la población venida desde Europa. Pese a no ser en ningún momento una colonia de poblamiento, es significativo que se pasara de los 3.000 europeos que vivían allí cuando se produjo la nacionalización del Congo, a más de 25.000 en 1930, un crecimiento que se ralentizó durante esa década debido a la crisis económica (en 1941 la cifra era de

\footnotetext{
1 HOCHSCHILD, Adam, El fantasma del rey Leopoldo: Codicia, terror y heroísmo en el África colonial, Barcelona, Península, 2002.

2 FIELDHOUSE, David K. Los imperios coloniales desde el siglo XVIII, Madrid, Siglo XXI, 1987, p. 298.
} 
27.790, lo cual sólo suponía un 0,27\% de la población total). La mayor presencia de colonos se produjo, además de por el engorde del cuerpo funcionarial, por la explotación intensiva de los recursos naturales (minerales, productos agrícolas y materias primas). El total de exportaciones del Congo Belga en la época en que Tintín se embarcaba hacia allí suponía más de dos millones de francos franceses, lo que la convertía en la primera colonia económica africana del área francófona ${ }^{3}$. Unas pocas grandes firmas eran las poseedoras de la concesión de tan lucrativo negocio: en 1932 operaban alrededor de doscientas sociedades, setenta y una de las cuales poseían los dos tercios del capital. Esas sociedades, a su vez, eran controladas por cuatro grupos financieros: Societé Générale, Groupe Empain, Groupe Cominière y Banque de Bruxelles; sólo el primero de estos grupos — participado en su gran mayoría por el Estado - invertía el cuádruple de capital que los otros tres juntos. Dichas inversiones iban destinadas a mejorar y -en la mayor parte de la región- a crear modernas infraestructuras. Se impulsaron las vías fluviales, se instalaron alrededor de 2.500 kilómetros de líneas férreas y «se construyeron fábricas, carreteras, ferrocarriles, minas y ciudades industriales muy modernas» ${ }^{4}$.

Con el tiempo, la población local vio sensiblemente mejoradas sus condiciones laborales. El patrono debía proporcionar al trabajador y a su familia habitación, equipo y cuidados médicos, además del sueldo mensual. Existían también sindicatos indígenas que eran tutelados por las autoridades, se prohibió el trabajo forzoso y se impuso una mayor vigilancia para que se cumplieran los contratos de trabajo y se respetaran todos los derechos. Pero para lograr un control efectivo y para que a su vez las infraestructuras resultaran rentables fue necesario realizar un reagrupamiento artificial de aldeas y grupos, creando un conjunto de unidades poblacionales lo bastante grandes como para ser administradas. Medidas que incrementaban todavía más la segregación entre el colectivo indígena y el europeo, y que destrozaban así cualquier posible equilibrio social, implantando un régimen perfecto en su género y especialmente eficaz, un régimen totalmente paternalista, por usar el término que el propio gobierno belga utilizaba para referirse a su política colonial en África todavía en $1958^{5}$ y que fue igualmente aplicado a Tíntin, cuya actitud para con los congoleños también se calificó de paternalista.

\section{TINTÍN VIAJA AL CONGO}

Cuando Tintín, acompañado de su perro Milú, toma el tren desde la estación de Bruselas camino del puerto de Amberes donde embarcará en el paquebote

3 MANNING, Patrick, Francophone sub-saharian Africa 1880-1985, Cambridge, Cambridge University Press, 1988, p. 51.

4 FORBATH, Peter, El río Congo: Descubrimiento, exploración y explotación del río más dramático de la Tierra, Madrid, Turner - FCE, 2002, p. 435.

5 Ídem, p. 437. 
Thysville -que toma su nombre de una localidad del Bajo Congo bautizada así en honor de un general belga-, acuden a despedirle un pequeño grupo de jóvenes admiradores, así como algún que otro periodista, muchos menos de los que le recibieron a su retorno de Moscú unos meses antes, pero muy representativo de la popularidad de la que empezaba a gozar por entonces entre sus compatriotas. De la misma manera, cuando el barco arriba a Matadi, tras una breve escala en Boma, una multitud de indígenas le espera en la dársena, a él y a su mascota, al grito de «¡Viva Tintín! ¡Viva Milú!», ante lo cual los protagonistas no se muestran demasiado sorprendidos, pues conocen hasta dónde llega su fama. No en vano, representantes de diferentes periódicos extranjeros como el New York Evening Press, el Daily Paper o el Diario de Lisboa acudirán a su hotel para intentar comprarle el reportaje que tiene previsto realizar sobre el Congo, objetivo que no lograrán, pues él, fiel a sus principios, no traicionará el compromiso adquirido con su rotativo, Le Petit Vingtième. La palabra dada es lo más importante, sin olvidarse que la cabecera para la que trabaja es mucho más generosa en sus ofertas.

Para entonces los lectores ya habíamos conocido al que sería el principal escollo de Tintín en el desarrollo de este viaje: Tom, un polizón de aspecto desarrapado, harapiento y mal afeitado, una de las típicas imágenes identificativas de los roles negativos en los tebeos infantiles clásicos. Será Milú quien descubra su presencia a bordo del Thysville; lo hará en uno de sus habituales interludios humorísticos (primero trasteando en el camarote de su amo, después enfrentándose a un lenguaraz papagayo y más adelante huyendo de los mosquitos, todo esto en las primeras páginas), paréntesis argumentales que beben a un tiempo de la dinámica de los primeros cortos de dibujos animados y del cine mudo cómico - no en vano Walt Disney y Charles Chaplin son dos de las primitivas y reconocidas influencias de Hergé-, y que ya muestran bien a las claras el dominio que Georges Remi empezaba a tener de las herramientas propias del cómic (onomatopeyas, metáforas visuales, líneas cinéticas). Pero Tom no parece un simple pasajero clandestino, esconde algo más, y justo al desembarcar jura entre dientes vengarse de nuestros héroes.

A la mañana siguiente, el reportero comienza a prepararse, alquila un viejo coche y contrata un guía, el pequeño Coco. Coco también responde a un estereotipo: el del ayudante indígena, un prototípico personaje secundario, pequeño, despistado, no demasiado valiente, aunque sí honrado, y que se somete en todo momento a su «señor», refiriéndose a sí mismo como «pitit noir». Ahí arranca ya directamente la aventura, o sería mejor decir las aventuras de Tintín en África, pues casi sin descanso se enfrenta a un cocodrilo, da caza a una decena de antílopes y se hace un disfraz con la piel de un gorila, además de apresar a Tom quien con anterioridad, y tras deshacerse fácilmente de un Coco que no opuso demasiada resistencia, le había robado el automóvil. Sin embargo, el prisionero logra huir en plena noche, un inconveniente al que el protagonista no otorga todavía demasiada importancia. Él considera más apremiante prose- 
guir su marcha, no sabemos muy bien con que objetivo, como no sea el presunto reportaje para el que todavía no ha escrito ni una sola línea ni ha tomado una sola instantánea.

El posterior incidente tendrá un carácter mucho menos dramático; de hecho, supone uno de los gags más recordados del álbum. Siguiendo un polvoriento camino llegan a un punto en el que éste se cruza con la vía del tren, y cuando intentan pasar el auto se queda cruzado en medio de los raíles. Mientras Tintín trata de mover el vehículo oye el característico sonido de un tren acercándose, parece que no tendrá tiempo de huir, se espera lo peor... pero ocurre lo impensable: al chocar contra su automóvil la locomotora ha volcado, descarrilando todos los vagones. La máquina ha quedado hecha pedazos, no quedando otro remedio que remolcar todo el convoy con su viejo coche. Para agradecerle su interés, y siendo como es conocido en todo el territorio, el rey de la tribu Babaoro'm reclama su presencia para invitarle a la caza del león, un viejo ritual reservado sólo para los más valientes. Con muchas dificultades el gran felino es cazado - aunque curiosamente se limitan a apresarlo sin darle muerte-, gracias a la brava intervención del pequeño Milú, siempre alerta para salvar a su amo. Lamentablemente esa hazaña perjudicará a la larga a Tintín, pues le granjeará una nueva enemistad, la de Muganga, el brujo de la tribu, temeroso de perder influencia sobre sus hermanos, impresionados por la actitud del explorador blanco. Justo entonces aparece, tras una choza, el temible Tom, deseoso de deshacerse de Tintín a la mínima oportunidad. Convence fácilmente al hechicero de que aquel es su común enemigo y de que tal vez juntos puedan acabar con su vida. Primero le acusan de robar el fetiche sagrado de los Babaoro'm, después provocan en su nombre un conflicto con los Matuvu, más adelante tratan de asesinarle con el método utilizado por la sociedad secreta de los aniota, e incluso le atan de pies y manos de la rama de un árbol al alcance de los cocodrilos, aunque nada de eso tiene éxito.

No se dan cuenta de que Tintín es mucho Tintín; el tiro les ha salido por la culata. Así, como consecuencia de haber resuelto con éxito todos y cada uno de dichos complots, Tintín es ahora nada menos que el jefe supremo de ambas tribus - los monarcas le han cedido su lugar-, ha conseguido la amistad eterna de un misionero destinado en aquella región, ha ayudado a un proveedor de animales para zoológicos europeos a conseguir un extraño ejemplar de leopardo, y ha aumentado su colección de trofeos de caza con los colmillos de marfil de un inmenso elefante. Sin embargo, Tom no se rinde (cosa que sí hace Muganga), y en el último intento por asesinar al joven héroe será él quien perezca. Por si fuera poco, resulta que Tom no estaba allí por casualidad, sino que era un secuaz del mismísimo Al Capone, enviado por éste a África para matar a Tintín, con el objetivo de impedir que el periodista lograra desmontar una red de tráfico de diamantes dirigida desde la distancia por el gángster de Chicago. Una red de la que el reportero belga no tenía noticia, pero que le llevará a visitar, en su siguiente aventura, el continente americano por primera vez. 


\section{UN POLÉMICO TEBEO JUVENIL}

Tan sencillo argumento estaba claramente destinado a los lectores más jóvenes. Su público potencial se hallaría dentro de un amplio grupo de edad comprendido entre los ocho y los quince años aproximadamente. Así lo corroboran detalles evidentes como la presencia de un perro que habla -o del que al menos se pueden conocer sus pensamientos-, o el ingenuo comportamiento de algunos de los personajes (Tom guarda en su bolsillo, por toda la selva, una carta con las instrucciones de su misión; la falsa declaración de guerra que los Babaoro'm envían a los Matuvu incluye insultos infantiles a su rey). Además, la propia figura de Tintín, el eterno adolescente, un muchacho sin vínculos afectivos ni familiares al que nada le retiene en casa, siempre preparado para partir hacia la aventura, permitía una rápida identificación, o al menos un deseo de identificación por parte de sus seguidores. $Y$ en ese contexto no resulta demasiado complicado rastrear en una segunda lectura los aspectos argumentales, formales y de contenido, que marcaron el posterior devenir de esta obra y le otorgaron la sempiterna etiqueta de racista que se le colgó desde después de la Segunda Guerra Mundial. No en vano Hergé realizó una nueva versión, ya a color, en 1946, en la que suavizó algunas escenas y eliminó algunas expresiones pasadas de moda relacionadas sobre todo con la religión y el nacionalismo. Llevó a cabo, en resumen, una actualización de su cuestionada historieta.

Pero incluso esos rasgos simplificadores - calificados como degradantes para con los congoleños-, resultan también crédulos, bobalicones, en la estela del tono general de la obra. Así, por ejemplo, cuando el paquebote Thysville está a punto de entrar en el puerto de Matadi, un indígena, que observa el barco desde la orilla, se gira hacia su hijo «Boule di neige» [Bola de nieve] para decirle que a bordo viajan sus héroes - el pequeño sostiene entre sus manos un ejemplar de Le Petit Vingtième- Obviamente, el nombre del pequeño, o la manera que su padre tiene de dirigirse a él, ha de interpretarse como un chiste, una broma que para algunos lectores puede resultar de dudoso gusto, que juega más con el contrasentido que con la provocación, más con la contradicción que con la ofensa, persiguiendo como objetivo último el hacer reír.

También se busca la diversión del lector en episodios como el del tren, objeto de polémicos análisis posteriores. Dejando de lado el hecho que esa grotesca imagen de las infraestructuras coloniales (locomotoras que no funcionan, vagones sin techo, una choza que hace las funciones de estación o de apeadero) no se corresponda demasiado con la situación en el Congo hacia 1930, lo más destacable es el retrato que elabora Hergé de los indígenas: se visten de forma ridícula, incorporando prendas occidentales a sus indumentarias habituales, se autodenominan «negritos» y sustituyen las palabras francesas que no conocen por onomatopeyas. Además son vagos, no quieren trabajar. Ahí tenemos al representante de la autoridad presente en la escena del accidente, que lleva encima un sombrero con pluma, una casaca con galones, un pantalón corto y unas botas altas, inten- 
tando escaquearse con un lánguido «moi fatigue». $U$ otro de los pasajeros, disfrazado con un sombrero de paja, una corbata rayada, una camisa de la que sólo conserva el cuello y los puños, y una falda larga, quien se excusa preocupado por mancharse tan elegante vestuario. Hasta Milú les ha de cantar las cuarenta, antes de que Tintín se ponga serio obligándoles a enderezar la máquina, eso sí, con él como supervisor. Negros trabajando a las órdenes de un blanco.

Incluso el rey de la tribu Babaoro'm posee como atuendo habitual una piel de leopardo a modo de capa, una banda que le cruza desde el hombro derecho, un sable y - cómo no- una corona. Sus soldados, al igual que los vecinos Matuvu, llevan encima trabucos, se cuelgan galones y se colocan sombreros peludos del XIX, pero eso sí: nada de camisas ni casacas. Parecen los restos perdidos u olvidados de los uniformes del ejército napoleónico, atuendos burlescos, como sus armas, o su manera de actuar en las situaciones difíciles ${ }^{6}$. En general los nativos son exageradamente manipulables. En un principio Muganga, el hechicero, les convence con suma facilidad de la culpabilidad de Tintín en la desaparición del ídolo de madera. Sin embargo, a renglón seguido, cambian de opinión gracias a las pruebas aportadas por el protagonista, quien se había molestado previamente en registrar con su cámara y su gramófono la conversación en la que Tom y Muganga planeaban vengarse de él. Y ese cambio de opinión es de tal magnitud que hasta llegan a ofrecerle al héroe ser su nuevo líder, sometiéndose nuevamente esta vez de rodillas - a la voluntad del colonizador.

La primera acción de Tintín como jefe Babaoro'm es mediar entre dos aborígenes que se pelean por un sombrero de paja. Como Salomón, él encontrará la solución partiéndolo por la mitad y contentando a ambos súbditos. Asimismo, curará a un enfermo suministrándole una simple gragea de quinina, siendo reconocido por esta acción como «gran brujo» o «boula-matari» (el apelativo que los indígenas le dieron décadas antes al explorador Henry Morton Stanley). Esos conocimientos técnicos que le hacen parecer superior, le posibilitarán nuevamente resolver, sin ayuda de nadie, el conflicto con el pueblo vecino. Con un simple imán y un poco de ingenio será capaz de derrotarlos, siendo reconocido como líder máximo de los Matuvu: incluso el propio rey le entrega su corona. Regios reconocimientos que no estan reservados únicamente a Tintín: Milú también conocerá su momento de gloria, incluyendo corona y trono, cuando sea confundido con un níveo enviado de los dioses por los pigmeos, quienes al parecer no habían visto jamás un fox terrier.

Ese espíritu es el que impregna todo álbum justo hasta la última plancha, ocupada en su totalidad por una gran viñeta en la que se desarrollan varias acciones al mismo tiempo. Siguiendo nuestro sentido de lectura, de izquierda a derecha y de arriba abajo, observamos en primer lugar dos tótems alzados en honor

6 «Las tribus que muestra parodian a su manera los ejércitos europeos de antaño» en GODDIN, Philippe, El arte de Hergé: 1907-1937, Barcelona, Zendrera Zariquiey, 2008, p. 75. 
de Tintín y de Milú. A los pies de la figura erigida a mayor gloria del reportero se halla un congoleño concentrado en su rezo, mientras que un perrito hace lo propio bajo la efigie de la mascota. Junto a ellos podemos ver una casucha con un rótulo en la puerta en el que se lee "Ka-fé», y en una de las mesas colocadas en el exterior dos indígenas, que comparten una botella se lamentan de la partida del protagonista («Dire qu'en Belgique tous les pitits blancs sont comme Tintin»). Igualmente apenados, y entre llantos, encontramos a un flamenco, plantado sobre una de las chozas de la aldea, a un pequeño indígena, a una tortuga y a un ratón; junto a ellos un anciano le promete a un joven que si Tintín no reclama su máquina de filmar en un año y un día, se la podrá quedar. Otro niño llora desconsolado pese a que su madre le repite que, si continúa berreando, no llegará a ser como su héroe. Finalmente, un segundo abuelo cuenta a quien le quiera escuchar que jamás en su larga vida conoció a nadie tan intrépido; algo similar a lo que comentan dos perros, aunque estos lo hagan sobre Milú.

Frente a estas evidencias no es extraño que se siga debatiendo cada cierto tiempo acerca de la idoneidad de recomendar esta lectura a los niños ${ }^{7}$, siendo como es un ejemplo de incorrección política. Pero, llegados a este punto, deberíamos plantearnos si ésa es de verdad la cuestión más importante. ¿No debería resultarnos más interesante saber porqué se da esa imagen de los africanos? ¿Cómo se explica la presencia constante de todos esos estereotipos en una de las más populares colecciones de cómics de la historia del medio?

\section{EL TRABAJO DE HERGÉ}

Una de las características que más se destacan en la obra de Hergé, junto con su dibujo de línea clara y su uso expresivo del color, es el proceso de documentación previo con el que buscaba dotar del mayor realismo posible a sus viñetas. El editor de cómics Carles Prats apunta lo siguiente: «El gran objetivo de Hergé —primero cuando Tintín pasa a tener su propia revista en 1946 y más tarde al crear su propio estudio en 1950- es el de la documentación minuciosa. Cada vez los álbumes consiguen una mayor riqueza de detalle y precisión en las imágenes»8. Una idea compartida plenamente por Michael Farr, quien en la introducción de su libro Tintín. El sueño y la realidad: La historia de la creación de Las aventuras de Tintín señala:

«Una de las claves de su éxito reside en la extrema precisión de los detalles, fruto de investigaciones infatigables. A lo largo de su vida, Hergé se procuró documentación de una riqueza y una variedad extraordinarias, clasificada metódicamente, archivada y catalogada. Todos los coches están fielmente representados,

${ }^{7}$ DE LAVELEYE, Didier, «Tintin au Congo... à interdire aux enfants, absolument!» (pp. 18-21) en MRAX, 179, 2007.

8 PRATS, Carles, «El lenguaje expresivo de Hergé: Una apuesta estética rigurosa y coherente» (pp. 33-36) en Vanguardia Grandes Temas, 3, 2007, p. 35. 
las armas se tomaron de catálogos de armeros, las cámaras fotográficas se dibujaron a partir de anuncios de Leica, las lanchas con motor fuera borda figuraban en la documentación recogida en los salones de náutica para este fin, los vestidos se copiaban de las revistas de moda, etc. Hergé archivaba hasta la obsesión todo lo que le parecía que algún día podría utilizar: documentos de toda clase y procedencia, postales ilustradas, catálogos de muebles y recortes de periódicos que cubrían numerosísimas áreas.

[...] Para cada uno de sus álbumes, excepto en los primeros episodios, en los que Tintín corría de una aventura a otra, Hergé, perfeccionista por naturaleza, se tomaba su tiempo"?.

Ambos subrayan el afán realista de Hergé, su deseo de conocer los escenarios a los que iba a enviar a su personaje, y ambos recalcan también que esa aspiración no se alcanza con plenitud hasta bien avanzada su carrera, cuando ya era un artista reconocido. Y si bien Prats habla de 1946, cuando Tintín contaba ya con doce títulos a sus espaldas, una fecha tal vez demasiado avanzada, Farr no es tan riguroso en ese sentido y se limita a nombrar «los primeros episodios», refiriéndose posiblemente a las cuatro primeras entregas desarrolladas entre Tintín au pays des Soviets (1929) y Les cigars du pharaon (1934). En esos cuatro primeros títulos, de una serie que alcanzará los veintitrés números, el esquema narrativo es muy similar y muy sencillo: el héroe se ve inmerso en una sucesión de incidentes, de mayor o menor gravedad, relacionados entre sí, e interrumpidos de vez en cuando por algún gag, hasta llegar a la resolución final, que en los cuatro casos es la misma, la desactivación de alguna banda o grupúsculo corrupto. Los espacios elegidos aunque no siempre por Hergé- eran además propicios para la aventura (Rusia, Congo, Estados Unidos de América y Egipto), por aquello que encerraban de mítico y de desconocido.

Parece evidente que aquí Hergé se dejó llevar por lo que creía conocer, por lo que pregonaba la literatura popular y por lo que los círculos sociales en los que se movía - católicos, monárquicos y conservadores- daban por supuesto. Se dejó llevar más por la leyenda que por el dato. En el caso que nos ocupa, y pese a que el joven Georges Remi visitará el Museo Colonial de Tervuren para informarse sobre la secta de los aniotas, estudiará las crecidas del río Congo, y revisará meticulosamente mapas y fotografías, el resultado será una visión del Congo desvirtuada por los tópicos. Una imagen muy extendida por aquel entonces, compartida por una gran mayoría de la población belga, tal y como lo reconocía él mismo en una serie de entrevistas concedidas al periodista Numa Sadoul en 1975:

«Era en 1930 [Hergé tenía 23 años]. Yo no conocía de ese país [el Congo] más que lo que la gente contaba en aquella época: «Los negros son unos niños grandes... Tienen suerte de que nosotros estemos allá», etc. $Y$ yo dibujé a estos afri-

9 FARR, Michael, Tintín: El sueño y la realidad. La historia de la creación de las aventuras de Tintín, Barcelona, Zendrera Zariquiey, 2002, p. 8. 
canos según estos criterios, con el más puro paternalismo, que era el de la época en Bélgica.

Para Tintín au Congo, al igual que para Tintín au pays des Soviets, ocurrió que yo estaba imbuido de los prejuicios del ambiente burgués en el cual vivía.

No intento excusarme; confieso que mis libros de juventud eran típicos de la mentalidad burguesa belga de entonces: jeran unos libros "belgacanes"! ${ }^{10}$.

Idea ésta sobre la que insistirá el periodista y biógrafo de Hergé, Pierre Assouline:

«La publicación de Tintin au Congo se produce sin polémica ni controversia. Por una razón: su espíritu está completamente en sintonía con los tiempos que corren. No racista, sino paternalista. En esa época, cuando Hergé escribe dentro de los bocadillos no se pregunta si debe escribir negro o «nègre», o si debe evocar los beneficios de la civilización occidental en el África negra poniendo entre comillas «los beneficios». Más tarde, cuando esas aventuras en el Congo se consideraron sospechosas de racismo, Hergé intentará disculparse invocando la mentalidad que reinaba entonces en la sociedad» ${ }^{11}$.

Durante el periodo de entreguerras, Bélgica vivió una constante inestabilidad política. Por un lado, la preeminencia en el gobierno de las formaciones católicas, vigente desde finales del siglo XIX hasta la Primera Guerra Mundial, se vio quebrada por la irrupción en el Parlamento del Partido Socialista, que inicia una tendencia que posibilitó la llegada de una serie de importantes cambios sociales - jornada laboral de ocho horas, creación de un sistema de seguridad social-, pero que impidió la implantación de gobiernos fuertes y duraderos. Por otro lado, las continuas diferencias entre las dos principales comunidades, valones y flamencos, no acababan de aplacarse. Esa debilidad interna, que permitió la entrada de movimientos de carácter fascista en las elecciones de 1936, se reflejó en cierta manera en el exterior: paulatina pérdida de peso en la escena internacional y recuperación de la neutralidad activa. En ese contexto político, al que hay que sumar las consecuencias de la depresión económica que se cebó sobre todo con la industria tradicional valona, resultaba vital el mantenimiento de las colonias, especialmente en el caso de una colonia rica como era el Congo. A pesar de esto, y como hemos comentado en el primer epígrafe, el Congo belga no fue nunca una colonia de poblamiento. La emigración colonial fue discreta, reservada a funcionarios, militares, misioneros y empresarios. Para la gran mayoría de ciudadanos belgas - Hergé y sus lectores entre ellos- aquellas tierras continuaron manteniendo su exotismo durante mucho tiempo, alimentado por las crónicas periodísticas y los noticiarios cinematográficos.

10 SADOUL, Numa, Conversaciones con Hergé, Barcelona, Juventud, 1986, pp. 49-50.

11 ASSOULINE, Pierre, Hergé, Barcelona, Destino, 1997, p. 50. 


\section{EN BUSCA DE VOCACIONES}

Georges Remi era hijo de un empleado y de una ama de casa. Proveniente de una familia modesta, escapa pronto de la monotonía del hogar a través del dibujo y de su afiliación a los grupos scouts católicos. El siguiente paso a partir de ahí, cumplidos ya los dieciocho años, es entrar a trabajar en la redacción del rotativo conservador Le Vingtième Siècle, órgano de expresión oficioso de la alta jerarquía eclesiástica belga. Allí entrará en contacto con quien habrá de ser una de sus mayores influencias y posiblemente la persona que más marcó el devenir de su carrera, al menos en los primeros años: el abate Norbert Wallez. Wallez, confeso anticomunista, antisemita, contrario a la democracia parlamentaria y admirador de la política de Mussolini en Italia, será considerado por Hergé como su padre moral e intelectual, responsable en gran medida del origen de Tintín. Es Wallez el que orienta a Hergé en esos años, el que le nombra redactor en jefe del suplemento infantil del periódico y el que le encarga la creación de «la historia de un adolescente y un perro, dentro de un espíritu misionero, virtuoso y católico »12. También será el abate quien elegirá el destino donde enviar al personaje, al menos en las dos primeras aventuras; a Rusia para denunciar la grave situación que se estaba viviendo allí con el triunfo de la revolución y la imposición de una dictadura comunista; al Congo buscando la inspiración misionera de las colonias.

Queda claro entonces que uno de los principales objetivos de enviar al intrépido reportero a aquel rincón del mundo, en lugar de hacerlo a América del Norte, como deseaba Hergé, era puro proselitismo: hacer patria y honrar las misiones. Las misiones católicas en las colonias belgas de África se instalan casi al mismo tiempo que se disuelve el llamado Estado Libre del Congo. El 26 de mayo de 1906, el rey Leopoldo II y el Papa León XIII firmarán la Carta Misionera del Congo Belga. A partir de ese momento, la función básica de esos enviados de la iglesia a tierras extrañas será la de civilizar a los infieles, tanto desde el punto de vista religioso, como desde el punto de vista patriótico. El propio Tintín parece conocer bien el tema y cuando ha de sustituir, en su visita a la misión, a un profesor enfermo, retoma la lección sin problemas: «Mes chers amis — dice a sus improvisados alumnos-, je vais vous parler aujourd'hui de votre patrie: la Belgique!». Por ello, el Estado destinará importantes ayudas económicas a las misiones para que los religiosos allí destinados se encarguen de la enseñanza primaria de los niños indígenas. Los poderes públicos se desentenderán de la acción educativa directa, al contrario de lo que harán otras potencias coloniales presentes en la zona como pueda ser el caso de Francia, que potenciaba una educación laica controlada desde la metrópolis. En el caso de Bélgica, fe y patria iban de la mano.

«Y al presente, bien lo sabéis, vamos a emprender una misión nueva. Llamados por el Rey al seno de esa región africana que él ha abierto a la civilización y al cristianismo, vamos a servir allí a las almas, y al mismo tiempo a servir a la patria.

12 Ídem, p. 40. 
¿Qué nos reserva el porvenir? Yo no lo sé ¿Más muertos que en las Indias? ... ¡No me parece! Ojalá podamos allí, como en las Indias, salvar las almas: a ese precio se muere con gusto; y allí al menos, en esas nuevas regiones, moriremos bajo los pliegues de la bandera nacional y descansarán nuestros cuerpos en tierra belga» ${ }^{13}$.

Hacia principios de la década de 1950, el jesuita Marcelo Paternostre, Delegado General para el Congo Belga del Comité Internacional para la Defensa de la Civilización Cristiana, presentó un informe ${ }^{14}$, que en su momento se editó en cuatro idiomas diferentes (francés, neerlandés, inglés y español), en el que comparaba la situación de aquella colonia antes de la llegada de las misiones católicas con la de esas fechas. En ese texto se definía al misionero como «el precursor de la civilización», destinado a evangelizar, a cristianizar — «el cristiano, el hombre renovado, reemplaza al mísero pagano»- y a acabar con toda una serie de sucias tradiciones (esclavitud, canibalismo, poligamia). El panorama inicial al que aquellos hombres se debían enfrentar era retador. Llegaban a un país desconocido en el que poblaciones enteras estaban mano sobre mano, incluso a riesgo de morir de hambre, mientras las tierras no estaban trabajadas. La razón era evidente: aunque el nativo "no siempre es perezoso», necesitaba «la presencia del blanco», ya que éste «estimulaba la actividad y desarrollaba las necesidades de esos indígenas que no producen». Eran como aquellos tristes pasajeros del tren que choca con el automóvil de Tintín, que no hacían otra cosa que quejarse, y que no se pusieron manos a la obra hasta que el hombre blanco les obligó a hacerlo.

«El negro no tiene la tradición del trabajo que posee el blanco. El hombre blanco tiene indiscutiblemente un adelanto de veinte siglos de civilización que le pone por encima del negro. Por eso no es justo siempre querer comparar el trabajador indígena, apenas pulido, al trabajador belga, quien es uno de los mejores obreros del mundo» ${ }^{15}$.

Una de las finalidades de esa apuesta decidida por la enseñanza era la de conseguir formar buenos trabajadores. El modesto sistema educativo que se desarrolló en la colonia estaba concentrado fundamentalmente en el grado primario y en el técnico-práctico, se utilizaba sólo la lengua vernácula y se reservaban los niveles de secundaria y universitario, así como la enseñanza en francés, exclusivamente para los europeos o para quienes estuvieran en contacto constante con estos. Se pretendía transmitir aspectos básicos acerca de la moral, la higiene, el progreso, el respeto y la simpatía por la empresa colonial, subrayando la dimensión religiosa a través de la evangelización. Buscaban transmitir el respeto por el trabajo.

13 TRICHT, Víctor Van, Obras amenas del padre Víctor Van Tricht de la Compañía de Jesús: Las misiones belgas. Conferencia familiar, Bilbao, El Mensajero del Corazón del Jesús, 1919, p. 46.

14 PATERNOSTRE, Marcelo, La obra civilizadora de los belgas en el Congo, Bruselas, Comité para la Civilización Cristiana en el Congo Belga, 1951.

15 Ídem, p. 81. 
«El indígena congolés debe comprender la dignidad del trabajo. Debe tener el sentido del trabajo bien cumplido. Pero su rendimiento es muy pobre. Esta comprobación explica el nivel relativamente bajo de la remuneración pagada para el trabajo del negro» ${ }^{16}$.

Llama la atención que dos décadas después de haberse publicado la primera aventura de Tintín en el Congo, y casi un lustro después de que viera la luz una segunda versión maquillada - y ya más políticamente correcta-, esa imagen de los congoleños siguiera enraizada en la sociedad belga, y por extensión en la europea, a través de una poderosa institución como era la Iglesia católica. El joven Hergé transmitió en su momento esos estereotipos, sin criticarlos, sin discutirlos, convencido de que así se comportaban los indígenas, y de las ventajas de la presencia del hombre blanco. $Y$ vino a coincidir punto por punto con la descripción que del colonizado, y del colonizador, trazaría más adelante - sus primeros artículos al respecto aparecieron en las revistas Esprit y Les temps modernes en 1957- el escritor tunecino Albert Memmi.

Memmi consideraba el colonialismo como un sistema basado en la explotación político-económica que destruye al colonizado y corrompe al colonizador, que es quien vive de esa explotación y de la opresión social ejercida sobre el indígena. La imagen clásica del colonizador, que por otro lado él trata de desmontar, es la de un aventurero noble, la del pionero con una misión cultural y moral. El conocimiento que el colonizador -y podríamos añadir al metropolitano- tiene del colonizado o del indígena, lo ha adquirido de «los libros de lectura de su infancia, de los documentales que había visto en el cine sobre determinadas costumbres, elegidas preferentemente por su rareza ${ }^{17}$. Un retrato que podríamos identificar con el de Tintín, periodista aventurero, repleto de valores, que se dirige hacia un lugar del que sólo conoce las leyendas y los mitos. Frente a Tintín o frente al colonizador, se halla el colonizado: perezoso, débil, ingrato y con escasas necesidades. Según Memmi, nada podría legitimar mejor el desvalimiento del colonizado que su ociosidad. «El retrato mítico del colonizado incluirá, pues, una increíble pereza. El del colonizador, el gusto meritorio de la acción ${ }^{18}$. El indígena necesita la protección del hombre blanco; necesita, al fin y al cabo, su presencia allí, una presencia superior. Y la relación lógica entre ellos se resume como un racismo vívido, no doctrinal, sino cotidiano, como un conjunto de conductas y reflejos aprendidos, ejercitados desde la infancia y reforzados y avalados por la educación.

\footnotetext{
16 Ídem, p. 79.

17 MEMMI, Albert, Retrato del colonizado precedido por retrato del colonizador, Madrid, Cuadernos para el diálogo, 1971, p. 59.

18 Ídem, p. 139.
} 


\section{DEFINICIÓN DE LOS TÉRMINOS}

Tras el análisis anterior surge una duda. Es evidente que el relato de Hergé sobre el que estamos trabajando participa de la doctrina paternalista hacia las colonias difundida entonces por la Iglesia católica y compartida por la mayoría de la sociedad belga. No obstante, eso no significa que refleje cómo era verdaderamente el Congo Belga en 1930. De hecho, la fotografía que nos presenta poco tiene que ver con aquella realidad histórica. Ni las infraestructuras, ni la influyente presencia de la población europea (a excepción del propio protagonista, del malvado Tom y del jefe de éste, sólo llegamos a conocer a dos extranjeros, un misionero y un oficial del ejército), ni la importancia de las explotaciones agrarias, ni el nivel de desarrollo urbano; nada de eso aparece en la páginas de Tintin au Congo. En este caso, el testimonio de Tintín no nos servirá a los historiadores para conocer mejor cómo era aquella región de África en el periodo de entreguerras del siglo pasado. Se trata, por tanto, de un testimonio equívoco; una prueba que no es tal, pues está falseada por las corrientes de pensamiento que caracterizan el entorno del autor y que él mismo entiende como válidas. Tendencias que calan de tal manera en la estructura argumental de la obra que, paradójicamente, la dotan de interés histórico justo a ese nivel, a nivel ideológico.

Los tebeos, es importante recordarlo, no eran exactamente por aquellos años un producto de autoría individual. Aunque lo firmara una única persona, responsable de guión e ilustraciones - si es que se acreditaba a los responsables, cosa que no era demasiado común en el mercado de la historieta para niños en las primeras décadas del siglo XX, ni en Europa ni en Estados Unidos-, por encima de él se situarían dos estratos más: el de los responsables editoriales y el de los responsables administrativos; figuras éstas que podían influir en el desarrollo y difusión de las obras, e incluso obligar a realizar cambios antes de que las páginas fueran editadas. Cuando hablamos del cómic, lo hacemos de un medio de comunicación de masas cuya popularidad y ansia por llegar a un público más numeroso podía hacerlo más permeable a las ideologías dominantes.

El cómic es una forma de expresión que debe ser entendida, en origen, tal que un producto editorial recreativo elaborado principalmente para ser vendido, y del cual se busca, a través de la distribución masiva, su rentabilidad en el mercado como una forma particular de ocio. Para alcanzar dicha meta hace uso de un soporte, el papel, barato, caduco, reutilizable y fácil de conseguir. Sin embargo, todas esas premisas son factibles a partir del fortalecimiento, en los países occidentales, de la industria editorial y de los nuevos mecanismos técnicos de difusión popular, que posibilitan una reproducción de los productos ilimitada y rápida. La implantación paulatina de la rotativa a partir de 1846, posibilitó la irrupción de fenómenos como las estampas populares o los grabados, a su vez ligados en su desarrollo a determinados cambios políticos y sociales de la época: consolidación de la burguesía, afianzamiento del liberalismo político o el nacimiento de la clase media urbana. 
La prensa incorporó la imagen al mundo del periodismo (sobre todo el chiste, la caricatura y el dibujo satírico, de intención política, social y moral) ya a principios del siglo XIX. Poco a poco, el concepto de periódico cambia con la introducción de litografías y por la influencia de los nuevos medios, destinados a la creciente población urbana inmersa en un segundo proceso de industrialización. Desde la década de 1870 y hasta la Primera Guerra Mundial se desarrollará, sobre todo en los Estados Unidos, el llamado New Journalism y el avance de la prensa hacia la difusión masiva. Este fenómeno se caracteriza por el cambio en la concepción del medio: ha pasado de ser un instrumento de difusión de, por ejemplo, un partido político o cualquier otra minoría a convertirse en un negocio millonario, en un medio de masas que será un agente de socialización, como consecuencia del nacimiento de un nuevo público, que al mismo tiempo impondrá cierta trivialización cualitativa e informativa. Es un proceso imparable fruto de la industrialización, de la sociedad de consumo (con el nacimiento del término competencia tal y como lo entendemos hoy día), los cambios tecnológicos, el crecimiento del público, la alfabetización masiva y el sufragio universal.

Con la introducción de la linotipia hacia 1886 o de la impresión en color a partir de 1896, técnicas que venían a sustituir al caro y dificultoso lavado en cobre, empezaron a proliferar, en la mayoría de países occidentales, las revistas ilustradas, principalmente de género burlesco y humorístico. Francia e Inglaterra son los precursores de esa corriente y el éxito de esas publicaciones se exporta a otros países (Alemania, Italia, España o Bélgica) donde las revistas tendrán una periodicidad fija y una aceptable acogida popular, apoyadas también por el previo desarrollo, como ya hemos señalado, de fenómenos como la literatura popular, la estampería o los folletines, géneros elegidos por las nuevas imprentas privadas que empiezan a multiplicarse. En esos diferentes soportes (periódicos y revistas satíricas) se llevaron a cabo los primeros experimentos narrativos que pueden entenderse ya como cómic. Anteriormente, y en esos mismos escenarios, surgirán los primeros ejemplos de los periódicos para la infancia, caracterizados por su paternalismo moralizante, didáctico y pedagógico, como correspondía a publicaciones producidas y dirigidas a la burguesía. Su objetivo era la formación de las futuras clases dirigentes a través de tratados de buenas maneras, de la defensa de la religión y del mantenimiento de las estructuras sociales imperantes.

Heredero directo de esas cabeceras pioneras es, décadas más tarde, Le Petit Vingtième - uno de los pilares, junto con la revista Spirou, del nacimiento del cómic belga, siempre a la sombra de los tebeos franceses-, suplemento para niños que con su éxito multiplicó la tirada del periódico del que dependía en más de 14.000 ejemplares, justo al inicio de la aventura africana de Tintín. Hergé, heredero reconocido del ilustrador francés Alain Saint-Ogan, supo aprovechar un momento en el que la historieta europea, al contrario que la norteamericana, todavía no se había desarrollado plenamente. Él será a partir de entonces uno de sus referentes, entre otras cosas por la rapidez con la que su personaje traspasaría fronteras geográficas e idiomáticas apareciendo entre 1930 y 1936 en publicaciones francesas (Co- 
eurs Vaillants), suizas (L'Écho Illustré) y portuguesas (O Papagaio), y alcanzando el reconocimiento del mercado con la recopilación de sus primeras aventuras en álbumes de tapa dura. Un éxito que sorprendía al propio autor, quien reconocía que dibujaba «para distraer a los niños y, de paso, a los mayores» ${ }^{19}$.

\section{TRABAJANDO CON CÓMICS}

Si partimos de una definición amplia de fuente histórica, como la que propone el profesor Alía Miranda ${ }^{20}$, no cabe duda que la historieta encaja potencialmente en dicha categoría. En ese sentido, no puede haber duda posible. Ahora bien, entre los fines de la generalidad de revistas de cómics, desde los puramente mercantiles y comerciales, hasta los proselitistas y doctrinarios, no figura el de convertirse en fuente histórica, por muy bien que reflejen su presente, o por muy influidos que estén por las ideologías o las corrientes de pensamiento contemporáneas. Nos equivocaríamos si no entendiéramos a la historieta como un medio narrativo mayoritariamente popular que persigue por encima todo, con o sin mensaje, el entretenimiento del lector (al menos hasta los años 60 del siglo XX con el estallido del cómic alternativo, o más recientemente con la irrupción del fenómeno de la novela gráfica). Cualquier uso historiográfico que se le pretenda dar se lo hemos de dar nosotros, siempre y cuando sea posible. Por lo tanto, lo que nos hemos de preguntar es cómo trabajar con ella: ¿Toda historieta es susceptible de ser interrogada históricamente? ¿Qué tipo de información nos puede aportar a los historiadores?

La única premisa a la hora de interrogar históricamente a un cómic es conocer las características de su particular lenguaje. La narratividad de la historieta se basa en la sucesión deliberada de elementos iconográficos propios, dispuestos en un orden determinado con un objetivo comunicativo o artístico. De acuerdo con Juan Antonio Ramírez, el relato debe ser ilimitado en cuanto a fondo y forma, no debe conocer barreras a la hora de elegir el lenguaje que quiere utilizar o sobre lo que quiere contar. Según este autor, un relato aúna la presencia de tres elementos básicos: la superación del instante mediante una sensación de temporalidad (de un antes y un después), la necesidad de un filtro que tamice la realidad para hacerla desembocar en el relato y, por último, una meta comunicativa. Tal consideración implica la transmisión de información, ya sea real o ficticia, situándose en un tiempo y un espacio elegidos por el autor. La meta principal se basa en un montaje hábil, en una realización eficaz que consiga hacerse legible, resaltando de ese modo el papel del lector. Para ello se deben utilizar convenientemente todas las herra-

19 FARR, Michael, Las aventuras de Hergé, creador de Tintín, Barcelona, Zendrera Zariquiey, 2009, p. 13.

20 «Fuente histórica es cualquier tipo de documento existente, cualquier realidad que pueda aportar testimonio, huella o reliquia, cualquiera que sea su lenguaje», en ALÍA MIRANDA, Francisco, Técnicas de investigación para historiadores: Las fuentes de la Historia, Madrid, Síntesis, 2005, p. 101. 
mientas comunicativas del cómic, sus diferentes unidades lingüísticas ${ }^{21}$. Mediante esa teoría descartamos la definición del cómic como mero «arte secuencial»; una única viñeta también es cómic pues a pesar de no seguir una secuencia encierra en su interior una sucesión de tiempos de lectura, tenga o no tenga palabras, y cumple los requisitos de los que habla Ramírez.

Esas imágenes, como vemos, pueden estar acompañadas por textos según una relación muy peculiar en la que tanto la imagen como el texto se mueven, en ocasiones, en niveles diferentes. A pesar de que siempre se ha definido a la historieta como un medio iconográfico-literario, por la presencia de ambos lenguajes, no hemos de olvidar que estamos frente a un medio eminentemente visual y es el dibujo el que determina la lectura, su ritmo y el nivel de información. Umberto Eco afirmaba que el texto es necesario para aclarar la ambigüedad del signo icónico, reproductor de algunas de las características del objeto representado sin llegar a compartirlas, pues no siempre es tan representativo como se cree ${ }^{22}$. Aceptada esa aclaración habría que matizarla en el caso de la historieta. Los ejemplos de cómics sin palabras son numerosos en cualquiera de los países tradicionalmente editores de este género y la simple viabilidad mercantil de esos productos durante años, demuestra la factibilidad de la imagen para hacerse entender por sí sola. No queremos negar con ello la importancia de la presencia de la palabra escrita en los tebeos, y menos aun teniendo en cuenta la especial plasmación gráfica elegida (onomatopeyas, bocadillos o globos, etcétera), pero está presente en todo caso en unas condiciones específicas.

Un segundo nivel de investigación haría referencia al cómic como objeto material. La familiaridad con las herramientas narrativas de dicho medio nos permitirá efectivamente conocer su contenido, aquello que cuentan las viñetas; sin embargo, resulta vital también estudiar el continente. Empezando por el formato de edición (si es una revista de historietas de diferentes personajes que continúan entrega tras entrega, si nos hallamos frente a un único volumen, o bien ante tiras de prensa incluidas en las páginas de los periódicos) hasta llegar al tipo de papel, pasando por la calidad de la reproducción, la utilización del color, su condición de primera edición o de reedición, o el precio de venta; aspectos todos ellos que nos aportarán en conjunto mucha información acerca de las condiciones de producción del producto y del tipo de lector al que iba destinado. Continente y contenido de un cómic son igualmente valiosos a la hora de utilizarlo como fuente, pues son rasgos definitorios que no se pueden desligar el uno del otro, dado que en la mayoría de casos es el tipo de contenido, ligado como es normal a un tipo determinado de lector/comprador, el que determina el continente.

En cuanto a las precauciones que hay que tomar en el momento de enfrentarse como historiadores a una historieta, podemos decir que son las obvias: las

${ }^{21}$ RAMÍREZ, Juan Antonio, Medios de masas e historia del arte, Madrid, Cátedra, 1976.

22 ECO, Umberto, Apocalípticos e integrados, Barcelona, Tusquets, 1995. 
mismas que con cualquier otro tipo de fuente histórica. El cómic que elijamos no nos va a aportar datos objetivos, ni tampoco una descripción fehaciente de hechos históricos, sino más bien una serie de matices que enriquecerán enormemente nuestro estudio. ¿Quiero esto decir que debemos entenderla como una fuente complementaria? Todas las fuentes históricas lo son, toda la información lograda se puede contrastar o completar con otras obtenidas a través de diversas huellas; no podemos basar una investigación histórica en un sólo testimonio, en un sólo documento. 